\title{
Acne fulminans in the course of oral isotretinoin treatment. Presentation of cases
}

\author{
Magdalena Kręgiel, Anna Żuchowska, Katarzyna Tomaszewska, \\ Agnieszka Wojciechowska, Anna Jędrowiak, Katarzyna Tabara, Wojciech Bienias, \\ Joanna Krzysiek, Andrzej Kaszuba, Ewa Trznadel-Grodzka
}

Department of Dermatology, Pediatric Dermatology and Oncology, Medical University of Lodz, ul. Kniaziewicza 1/5, 91-347 Lodz, Poland

Corresponding author: Magdalena Kręgiel, MD, E-mail: magdalenakregiell@gmail.com

\begin{abstract}
Isotretinoin is considered a gold standard in treating severe cases of acne. It brings lots of benefits but on the other hand can cause series of undesirable side-effects. I present 2 cases of patients suffering from acne fulminans in the course of treatment with oral isotretinoin. Acne fulminans is a very severe systemic disease and its course is difficult to foresee. The most important is rapid diagnosis and implementation of treatment. Systemic corticosteroids combined with isotretinoin or high doses of antibiotics are the most effective. The alternative methods are: dapsone, infliximab.
\end{abstract}

Key words: Acne fulminans; Pseudo-acne fulminans; Isotretinoin; Erythema nodosum

\section{INTRODUCTION}

Isotretinoin, being the most effective drug exerting an effect on all pathogenic factors of acne vulgaris, is more and more commonly applied in dermatological outpatient care. Since 1971, that is the time when Bollag and Geiger started their first clinical tests, isotretinoin has been widely administered, which confirms its safety. Isotretinoin applied orally, which is commonly considered a gold standard in treating severe cases of acne, can bring lots of benefits but unfortunately can also result in a series of undesirable side-effects, mostly of mucocutaneous type [1]. In 98\% of patients cheilitis and skin dryness can be found while $20-65 \%$ of them manifest conjunctivitis and marginal blepharitis, contact lens intolerance, erythema and itching of the skin, eczema as well as nasal and anal bleeding. Moreover, isotretinoin reduces salivation, which results in an increased risk of caries. Night vision and colour perception deficiencies as well as headaches, myalgia and ostealgia, mood changes and aggressive behavior are also reported [2]. $25 \%$ of patients demonstrate higher triglyceride and cholesterol as well as an increased HDL/LDL ratio. In $15 \%$ of patients, thus quite often, the aminotransferase level (AST/ALT) is also elevated. Such disturbances are however temporary and they usually cease after the completion of the treatment. Isotretinoin, just like all other retinoids, shows strong teratogenic influence on the foetus.

From the clinical point of view the most essential problem is significant exacerbation of clinical condition in $5-8 \%$ of patients during the first 6 to 8 weeks of therapy. Literature reports single cases in which the commencement of oral isotretinoin treatment is associated with the occurrence of: agranulocytosis, sacroiliac arthritis and demyelinating peripheral neuropathy $[3,4]$, demyelinating lesions within the cerebellum which causes tinnitus and syncopy, foci of cerebral ischemia resulting in facial hemiparesis, Sweet's syndrome, enteritis and pyoderma gangrenosum. Isotretinoin can also cause generalized facial edema as well as affect the patient's psyche by worsening depression symptoms or releasing panic attacks. However, the most serious undesirable dermatological

\footnotetext{
How to cite this article: Kręgiel M, Żuchowska A, Tomaszewska K, Wojciechowska A, Jędrowiak A, Tabara K, Bienias W, Krzysiek J, Kaszuba A Trznadel-Grodzka E. Acne fulminans in the course of oral isotretinoin treatment. Presentation of cases. Our Dermatol Online. 2017;8(2):210-214.

Submission: 05.07.2016; Acceptance: 05.10.2016

DOI:10.7241/ourd.20172.57
} 
effect is the potential occurrence of pseudo-acne fulminans symptoms.

The name Acne fulminans (AF) was first introduced in 1975 by Plewig and Kligman to illustrate the sudden course of illness [5]. Pathogenesis of AF remains unclear despite intensive research. Results which have been received so far indicate that immunological factors (hipergammaglobulinemia, haematuria, circulating immune complexes) might substantially contribute to the occurrence of the disease. AF develops de novo or can be induced by an ongoing inflammatory process - as progression of acne vulgaris.

Cases of drug-induced AF are extremely rare. There are some reports in medical literature about AF developing in boys treated with high doses of testosterone and in young males using anabolic steroids along with B vitamins.

Acne fulminans mostly affects white boys under 16 , diagnosed with mild to moderate acne vulgaris. $\mathrm{AF}$ is characterized with a sudden onset and a very rapidly progressing severe course. Inflammatory lump eruptions and cystic skin abscesses leading to hemorrhagic necrosis are accompanied by general symptoms. Fever, weakness, muscle and joint pains as well as weight loss are the main signs of AF. Increased inflammatory markers like ESR, CRP as well as anemia, abnormalities in laboratory liver tests results, proteinuria or haematocyturia [6] can be observed. Additionally, cases of sterile osteomyelitis with osteolysis located mainly in the sternoclavicular joint, sacroiliac joint and long bones can be observed quite often. In $10 \%$ of patients spine hyperostosis occurs. In the event of bone pains, infections or cancer should be ruled out first. The final diagnosis has to be based on biopsy results $[7,8]$.

Some cases of erythema nodosum or pyoderma gangrenosum in the course of AF have been reported [9].

Skin lesions, characteristic for AF, tend to leave scars, which leads to permanent scarring. Such patients feel socially excluded. For this reason, it is highly important to make an early diagnosis so that effective treatment can be implemented. However, in some cases of rapid exacerbation of acne, induced by isotretinoin administration, systemic symptoms may not occur. Such symptoms are recognized as "pseudo-acne fulminans" or "acne fulminans sine fulminans" $[9,10]$.

\section{CASE REPORT}

\section{Case 1}

A female patient treated in a District Dermatological Outpatient Clinic for acne vulgaris for the last 4 years and psoriasis since she was 4-years-old.

Benign lesions are effectively controlled with standard, topical treatment and have remained in remission for the last 5 years. The patient's father suffers from psoriasis and her mother used to have severe acne vulgaris with tendency to scarring. The patient's 20 year-old sister also developed AF in the early stage of treatment with isotretinoin.

The 19 year-old female patient, $60 \mathrm{~kg}$ body weight, suffering from acne papulous of the face, forehead, nose and chin areas for the last 4 years, started her therapy with conventional, topical application of adapalene, tretinoin, benzoyl peroxide, antibiotics and zinc preparations. Since the topical treatment remained ineffective, the patient was administered a systemic therapy with lymecycline. Initially, the daily dose was $0.6 \mathrm{~g}$ and later it was reduced to $0.3 \mathrm{~g}$. The patient was next administered $0.2 \mathrm{~g}$ doxycycline and $0.5 \mathrm{~g}$ azithromycin per day for 3 days and then once a week. The total period of the combined oral antibiotic treatment and topical treatment lasted above 8 months and did not result in any clinical improvement. Thus, oral isotretinoin treatment with a daily dose of $30 \mathrm{mg}$ $(0.5 \mathrm{mg} / \mathrm{kg} \mathrm{bw})$ was initiated. After 10 days of the therapy disease symptoms rapidly exacerbated. The disease manifested with numerous, extensive, papular lesions, inflammatory nodules, pimples infiltrated at the base, necrotic ulcers with gelatinous substance and layers of yellowish crust formations, covering the whole facial area, except for the eyelids. The eruptions demonstrated a tendency to scarring. Edemas in the root of the nose and inter-eyebrow area were observed (Figs.la- lc). The above symptoms were accompanied with $38.5^{\circ} \mathrm{C}$ fever and muscular pains of big joints and the spine. The above conditions resulted in the patient being referred to further hospital treatment in the Department of Dermatology, Paediatric Dermatology and Oncological Dermatology in the Bieganski Hospital in Lodz.

The patient was administered diprophos ( 1 ampoule $\mathrm{im}$.), dexamethasone $1 \mathrm{mg}$ /day, tetracycline $1.5 \mathrm{~g} /$ day and topical astringents and disinfectants (1\% tannin compress + sulphur pulp with detreomycin). Essential 
laboratory parameters remained normal, except

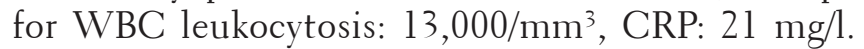
Radiological examinations excluded osteomyelitis of sternoclavicular bones. After 7 days of treatment general symptoms ceased, the local condition slightly improved and facial edema lessened. Yet, new inflammatory papules continued to appear. After 14 days of therapy tetracycline was replaced with azithromycin applied at daily doses of $0.5 \mathrm{~g}$.

Other recommendations were followed as before. After the first 3 weeks, intensive purulent lesions started to disappear gradually. Also, papulopustular eruptions got absorbed (Fig. ld). Finally, the four-month treatment brought about a significant improvement. However, some atrophic or hypertrophic brown scars remained.

\section{Case 2}

A 15-year-old male patient with a history of moderate papulopustular acne, affecting the face, back and neckline area, suffering for 3 years, was treated with oral isotretinoin. No systemic or topical treatment had ever been administered before. Both the patient's parents suffered from acne vulgaris in their youth; his siblings, aged 10 and 12 , had negative disease records.

The male patient, $50 \mathrm{~kg}$ body weight, treated in an outpatient clinic, with oral isotretinoin, at daily doses of $30 \mathrm{mg}$ (0.6 mg per kilogram of bw). Laboratory follow-up examinations, carried out in week 4 of treatment showed no abnormalities and no general disorders were noted. However, in the second week of isotretinoin application, a sudden and severe exacerbation of acne occurred. After another 6 weeks the patient's condition was continually deteriorating. He reported weakness, a feeling of fatigue, periodical joint and muscle pains and the body temperature was $38^{\circ} \mathrm{C}$. The face, neckline and back skin area was covered with extensive, painful pustules and inflammatory lumps that broke, which led to a formation of hemorrhagic and necrotic lesions and gelatinous ulcerations with folded margins. Some of the lesions were covered with layers of brown and yellow crusts (Figs. 2a and 2b). Moreover, the patient reported pain and edema in the left lower limb. A physical examination of the anterior, medial and lateral surface of his left shin revealed some visibly separated, painful and acutely inflamed lumps, 5 to $8 \mathrm{~cm}$ in diameter (Fig. 3). The patient was therefore referred to further treatment in the Department of Dermatology, Paediatric Dermatology and Oncological Dermatology in the Bieganski Hospital in Lodz. The

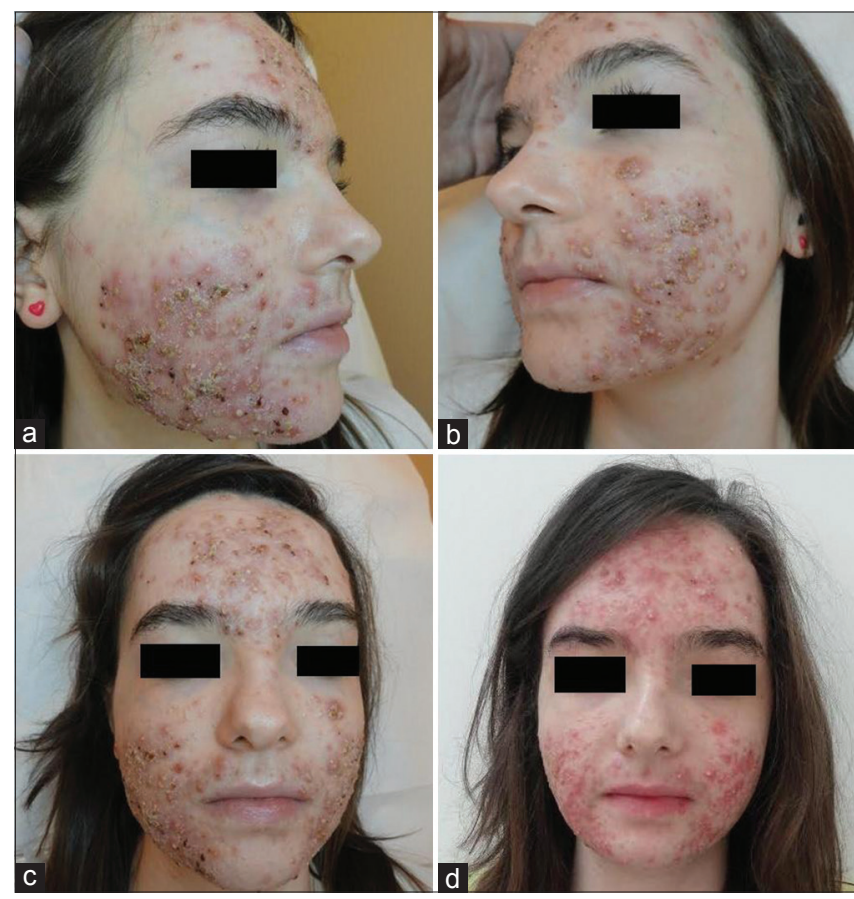

Figure 1: (a-d) Case 1. A-C: 19-year-old girl presenting acne fulminans. D: Case 1. After the first 3 weeks of treatment.

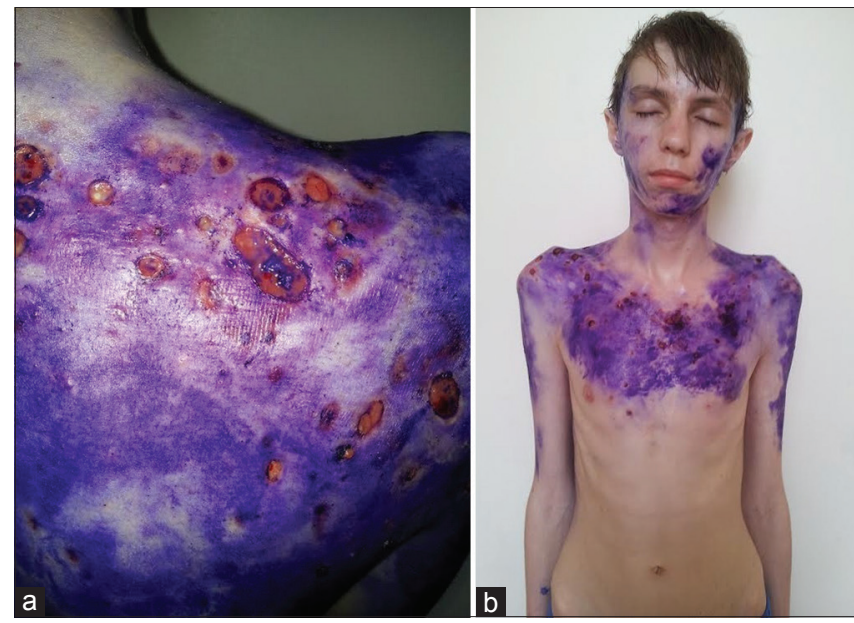

Figure 2: $(a-b)$ Case2. 15-year-old boy presenting Acne fulminans.

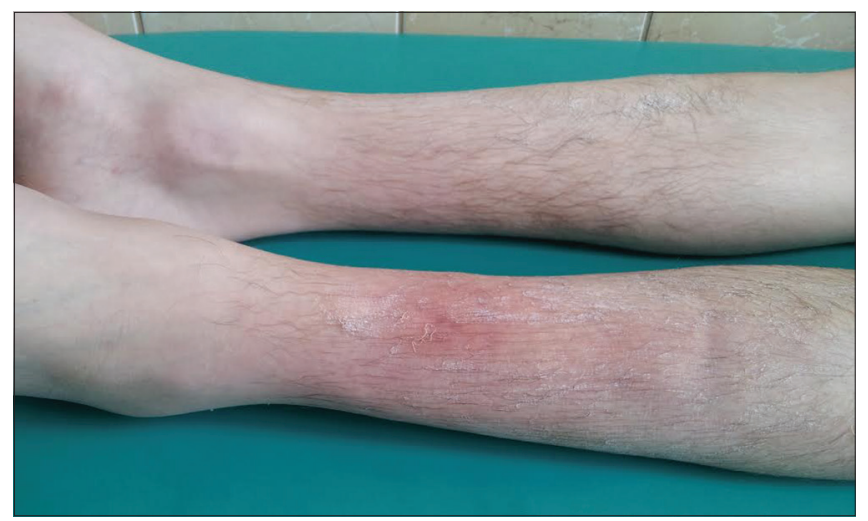

Figure 3: Erythema nodosum developed in the first phase of acne fulminans. 
following abnormalities were observed in laboratory

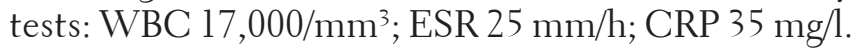
Isotretinoin treatment was discontinued. Instead, the patient was administered dexamthasone $1 \mathrm{mg}$ daily p.o., omeprazole $40 \mathrm{mg}$ daily p.o., rovamycine $6 \mathrm{mln}$ I.U. p.o, biodacinum $0.5 \mathrm{~g}$ daily iv. (for 10 days and then tetracyclium $1.5 \mathrm{~g}$ daily p.o.). The patient was also ordered topical treatment of acne lesions with $2 \%$ gentian violet water solution combined with $0.08 \%$ gentamycine ointment. The patient's shank was treated topically with gentamycine-hydrocortisone cream along with compresses of $2 \%$ water-alcohol solution of ichthyol.

Soon there was a visible improvement in the patient's clinical condition. In the first phase general symptoms ceased: fever as well as joint and muscle pains. Ulcerative lesions on the trunk and eruptions on the shank gradually started to clear. Currently, on day 10 of hospital treatment, the patient reported an improvement of his general condition. In further outpatient treatment the patient will be still administered tetracycline and dexamethasone $0.5 \mathrm{mg}$ per day. However, the doses will be gradually diminished.

\section{DISCUSSION}

Acne fulminans is the most dangerous complication of acne vulgaris treated with oral isotretinoin. Predisposing factors for the occurrence of AF include: male sex, age 13 - 16, numerous blackheads on the face and trunk as well as at least two inflammatory nodules in the facial area $[11,12]$.

Some authors recommend using lower doses of isotretinoin (0.2-0.3 mg per $\mathrm{kg}$ of $\mathrm{bw}$ ) in the initial phase of treatment to reduce the risk of acne exacerbation or AF occurrence. Alternatively, they also recommend treating a patient with systemic antibiotics before application of isotretinoin.

Patients from a group with a high risk of developing AF (young males 13-16 years old) seem to cause the greatest therapeutic problems. Acne fulminans is supposed to be prevented with methods such as mechanical clearage of blackheads, systemic antibiotic or steroid therapy, carried out before or on commencement of isotretinoin administration.

The patient presented in Case 2 was in a risk group due to his age, sex, location and exacerbation of lesions. In spite of standard oral isotretinoin treatment with a dose of $0.6 \mathrm{mg} / \mathrm{kg}$ of bw (recommended dose is $0.5-1.0 \mathrm{mg}$ of bw) [13-16], the patient developed AF. An analysis of the case leads to a conclusion, that before implementing isotretinoin treatment, all possible precautions should be taken. They must include: careful consideration of possible risks and, in cases of prior positive medical history, implementation of an antibiotic therapy in order to reduce inflammation.

Some dermatologists avoid isotretinoin treatment in boys under 17 even if they are affected by acne lesions which are antibiotic-resistant since they fear that such patients might develop AF. This management method seems logical and reasonable. It is hard to state if this very patient would have avoided AF if earlier conventional treatment of acne vulgaris had been employed because none of preventive methods was introduced. The patient also developed erythema nodosum in the first phase of AF. Such cases have been rarely described in professional literature. The etiology of erythema nodosum is strongly related to bacterial infections, especially streptococcus, sarcoidosis, tuberculosis, inflammatory bowel diseases, immunological disorders and hypersensitivity to pregnancy hormones.

Some sources also quotes relationships between AF and rheumatological diseases, mycoses, ongoing neoplasms and applied drugs, such as, antibiotics or contraceptives [17]. Erythema nodosum is also explained as a result of an influence of immune complexes, occurring in the course of AF therapy $[9,13]$. The etiopathogenesis of acne fulminans and erythema nodosum still remains not precisely or fully explained.

Contrary to the patient mentioned above, the patient presented in Case 1, cannot be included in a AF risk group. The female sex, aged 19, prior numerous antibiotic therapies were not predisposing factors for development of AF. This case however makes us carefully manage cases of acne vulgaris qualified for standard oral isotretinoin treatment. In this patient the medical history for detecting AF before introducing isotretinoin appeared negative because both the sisters were administered isotretinoin simultaneously, which triggered AF symptoms [14]. The fact that both the sisters developed AF might be a ground for drawing a conclusion that there are genetic predispositions for AF development. In 1992 Wong et al. described a genetic occurrence of $\mathrm{AF}$ in sisters, in whom the disease 
was accompanied by severe joint symptoms [18]. A case of twins treated with oral isotretinoin can also confirm an important role of genetic factors in AF development.

One of them developed severe eruptive pyogenic granulomas, the other one - fully symptomatic AF.

Current studies show no relation between acne fulminans and psoriasis. Prognosis in the course of $\mathrm{AF}$ is good. However, extensive and disfiguring scars seem to be greatest problem, which can be solved by commencement of effective treatment, followed by constant monitoring of the patient. Systemic glucocorticosteroids (GCS) seem to bring greatest benefits, e.g. prednisone applied at a daily dose of $0.5-1.0 \mathrm{mg} / \mathrm{kg}$ of bw. According to guidelines of the National Dermatological Society on acne vulgaris, the most effective and quickest results can be achieved after re-administration of isotretinoin in 2 and 4 weeks of the therapy, with a dose of $0.5 \mathrm{mg} / \mathrm{kg}$ of bw, followed by a gradual reduction of GCS doses. An alternative approach might be a combined therapy of systemic GCS and antibiotics [15-16], as it was performed in the two patients presented above.

Optional treatment presented in medical literature involves: dapson, initially applied at a dose of $50 \mathrm{mg}$ per day, then at doses of 100-150 mg per day [6] as well as a biological drug infliximab (anti-TNF- $\alpha \mathrm{Ig}$ ), which is considered "the last resort drug" if standard treatment appears to be ineffective [19].

Acne fulminans in the course of treatment with oral isotretinoin is a very severe systemic disease and its course is difficult to foresee [20]. Currently, as isotretinoin therapy is a golden standard in treatment of severe acne vulgaris, we can expect an increased incidence of $\mathrm{AF}$ in the future. We should point out risk factors and genetic predispositions for development of this disease.

\section{Consent}

The examination of the patient was conducted according to the Declaration of Helsinki principles.

\section{REFERENCES}

1. Bergler-Czop B, Brzezińska-Wcisło L. Skórno-śluzówkowe objawy uboczne retinoidów doustnych w terapii trąaziku pospolitego. Post Nauk Med. 2012;10:777-86.

2. Żaba R. Special paper safety of the treatment with retinoids. Post Dermatol Alergol. 2006;4:161-74.

3. Eksioglu E, Oztekin F, Unlu E, Cakci A, Keyik B, Karadavut IK. Sacroilitis and polyneuropathy during isotretinoin treatment. Clin Exp Dermatol. 2008;33:122-4.

4. Aydogan K, Karli N. Effects of oral izotretinoin therapy on peripheral nerve functions; a preliminary study. Clin Exp Dermatol. 2007;32:81-4.

5. Plewig G, Kligman AM. Acne: morphogenesis and treatment. Springer. Berlin. 1975;196.

6. Pastuszka M, Kaszuba A, Kurowska-Poznańska K. Trądzik piorunujący (acne fulminans). Dermatol Prakt. 2010;2:52-8.

7. Geller AS, Alagia RF. Sacroiliitis after use of oral isotretinoinassociation with acne fulminans or adverse effect? An Bras Dermatol. 2013;88:193-6.

8. Sarifakioglu E, Onur O, Kart H, Yilmaz AE. Acute myopathy and acne fulminans triggered by isotertioin therapy. Eur J Dermatol. 2011;2:794-5.

9. Thomson KF. Cunliffe WJ. Acne fulminans ,sine fulminans”. Clin Exp Dermatol. 2000;25:299-301.

10. Grando LR, Leite OG, Cestari TF. Pseudo-acne fulminans associated with oral isotetinoin. An Bras Dermatol. 2014;89:657-9.

11. Demircay Z, Kus S, Sur H. Predictive factors for acne flare during isotretinoin treatment. Eur J Dermatol. 2008;18:452-6.

12. Dreno B, Bettoli V, Ochsendorf F et al.An expert view on the tratment of acne with systemic antibiotics and/or oral isottetinoin in the light view of new European recommendations. Eur J Dermatol. 2006;212:168-76.

13. Tan BB, Lear JT, Smith AG.Acne fulminans and erythema nodosum during isotretinoin therapy responding to dapsone.Clin Exp Dermatol. 1997;22:26-7.

14. Joly P, Prost C, Gaudemar M, Revuz J. Acne fulminans triggered by isotretinoin therapy, Ann Dermatol Venerol. 1991;118:369-72.

15. Żaba R, Schwartz RA, Jarmuda S, Czarnecka-Operacz M, Silny W. Acne fulminans: explosive systemic form of acne. JEADV 2011;25:501-7.

16. Szepietowski J, Kapińska-Mrowiecka M, Kaszuba A, Langner A, Placek W, Wolska H, Matusiak $\ell$. Trądzik zwyczajny: patogeneza i leczenie.Konsensus Polskiego Towarzystwa Dermatologicznego. Przeg Dermatol. 2012;99:649-73.

17. Schwartz RA, Nervi SJ.Erythema nodosum: a sign of systemic disease. AM Fam Physician. 2007;75:695-700.

18. Wong SS, Pritchard MH, Holt PJ. Familial acne fulminans. Clin Exp Dermatol. 1992;17:351-3.

19. Iqbal M, Kolodney MS. Acne fulminans with synovitis-acnepustulosis-hyperostosis-osteitis (SAPHO) syndrome treated with infliximab. J Am Acad Dermatology. 2005;52:118-20.

20. Charakida A, Mouser PE, Chu AC. Safety and side effects of the acne drug, oral isotretinoin. Expert Opin Drug Saf. 2004;3:119-29.

Copyright by Magdalena Kręgiel, et al. This is an open access article distributed under the terms of the Creative Commons Attribution License, which permits unrestricted use, distribution, and reproduction in any medium, provided the original author and source are credited. Source of Support: Nil, Conflict of Interest: None declared. 